\title{
Brief Report \\ Effective Handling of COVID-19 Pandemic: Experiences and Lessons from the Perspective of South Korea
}

\begin{abstract}
Abdul Majeed
Department of Computer Engineering, Gachon University, Seongnam 13120, Korea; ab09@gachon.ac.kr; Tel.: +82-10-9503-9597

Abstract: The ongoing pandemic (i.e., novel corona virus disease 2019 (COVID-19)) is a major crisis that humanity is facing across the globe. In response to COVID-19, every country has designed and enforced various mechanisms to control its spread, and save their citizens from this deadly disease. Besides the general containment strategies, the use of technology and person-specific data collection and processing also vary from country to country. In this brief case report, we describe the measures that South Korea (SK) has adopted in order to curb the spread of COVID-19, and the success of SK in keeping the cases at a manageable level since the start of this pandemic until present via extensive use of technology. Specifically, we describe the data collected to control this pandemic, technical framework in place to ensure co-ordination with different authorities, containment strategies, and major breakthrough SK achieved when sporadic clusters emerged throughout the nation. With this brief overview, we aim to update the research community about the unprecedented efforts SK made, utilizing previous pandemic experiences, and the successful results they have obtained so far amid this pandemic, leveraging technology.
\end{abstract}

Keywords: COVID-19; pandemic; technical framework; sporadic cluster; pandemic experiences

\section{Introduction}

Novel coronavirus disease 2019 (COVID-19) has become an unanticipated and unprecedented crisis for the whole world. It has forced the closure of educational institutes, entertainment facilities, and international/domestic events across the globe [1]. The future of many events to be held in 2021, including the Olympics to be held in Japan in July and the cricket world cup to be held in India in October, seem uncertain. The aviation industry is also reeling, and many aviation operators have turned their focus from air travel to other sectors, including coffee shops and bars, etc. Although the situation is improving in many countries across the globe, returning to normal will likely take more time. In the presence of a vaccine, there is a hope of returning to normalcy soon, but delivering the vaccine fairly to every individual across the globe is one of the major challenges [2]. In addition, motivating people to take the vaccine is proving to be challenging in many territories and regions. Therefore, substantial efforts are needed to achieve this common goal to eradicate this pandemic as soon as possible.

In response to COVID-19, every nation adopted different containment strategies, from strict border closures to bans on gatherings of three or more people. Similarly, the use of technical measures varies from country to country. In this work, we intend to solely share the experiences from South Korea (SK); therefore, we discuss the technical mechanisms employed in SK, solely, along with other parameters. To date, the number of cases and tests performed in SK are listed in Figure 1. From the analysis, it can be seen that SK has managed this pandemic well and kept the cases at a manageable level through different containment strategies. Apart from the awareness programs, the use of technology was higher to fight the pandemic. In addition, many latest applications were developed to effectively control this pandemic and alert people to stay away from 
contaminated places [3]. Furthermore, they designed mechanisms to collect data from each organization to fight with this pandemic through the shared responsibility concept.

\section{Cases and tests data of South Korea $\left(27^{\text {th }}\right.$ June 2021)}

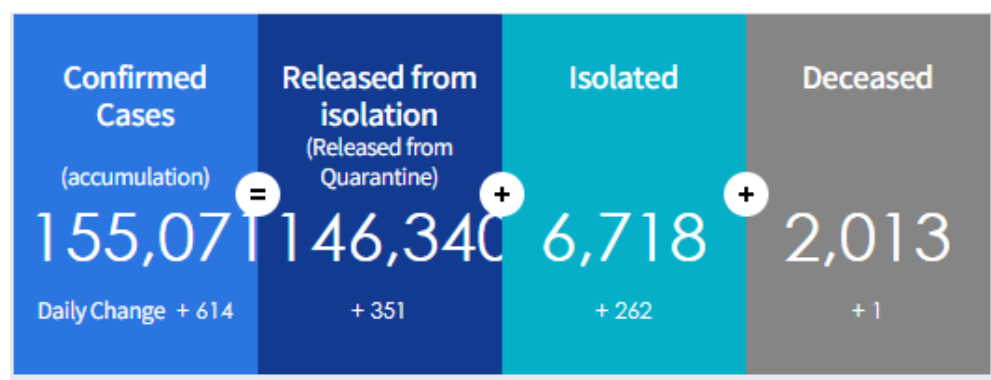

(a) Cases in SK (as of 12am on June 27, 2021).

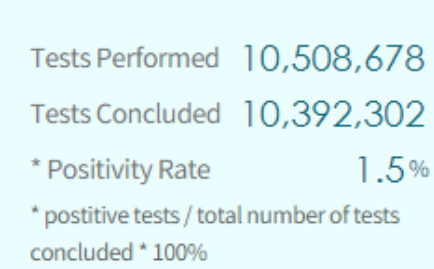

Positive Results(Confirmed Cases) 155071/1.5\% In Progress 116376/1.1\%

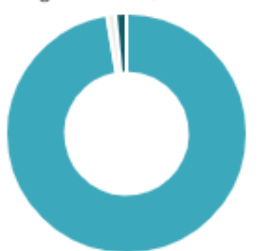

Negative Results 10237231/97.4\%

(b) Testing in SK (as of 12am on June 27, 2021).

Figure 1. Overview of cases and test data from South Korea.

The detailed overview about the timeline of epidemic development and public health actions in SK are summarized in Table 1.

Table 1. Overview of timeline of epidemic development and public health actions.

\begin{tabular}{ccc}
\hline Serial No. & Category & Description/value \\
\hline 1. & First case & 20 January 2021 \\
2. & Total cases (19 August 2021) & 230,808 \\
3. & Positivity rate (19 August 2021) & $1.9 \%$ \\
4. & Deceased & 2191 \\
5. & Fatality rate & $0.95 \%$ \\
6. & Recovered & 201,235 \\
7. & Highest daily tally (9 August 2021) & 2134 \\
8. & Fully vaccinated people & 10.81 million $(21.1 \%)$ \\
9. & First dose people & 24.30 million $(47.3 \%)$ \\
10. & Highest death toll (26 august 2021) & 20 people \\
\hline 1. & Mask wearing & $100 \%$ \\
2. & Compliance with govt. guidelines & Very high \\
3. & Sanitization & Regular \\
4. & Ventilation & Regular \\
5. & Work from home & Nearly 30\% people \\
6. & Daily activities & Mostly online \\
\hline
\end{tabular}

The SK government faced resistance from their citizens due to fine-grained data collection and corresponding privacy issues during the pandemic [4]. However, the adoption was lower for those mechanisms that solely collect detailed data constantly [5]. Despite many challenges, SK is the only country in the world that did not enforce a lock down. They sustained the economy, and almost all sectors are working normally 
by following the government's guidelines. By digital means, they can quickly trace the infected people without disturbing the economy or citizens. In addition, the apps and systems in place are multidisciplinary, meaning law and enforcement agencies and other concerned departments are working collectively to control this pandemic. Above all, the public compliance with the guidelines designed by the SK Government is higher. Although some studies have described the experiences of SK to some extent, they failed to cover the experiences from broader perspectives. In this concise study, we describe the experiences of SK and the major breakthrough they attained during this pandemic using technical measures.

\section{Effective Handling of COVID-19 Pandemic by South Korea}

In this section, we concisely describe the main motivations behind the effective handling of the COVID-19 pandemic by SK. In this regard, we describe the data that the SK government collected and processed during this pandemic to fight the pandemic.

\subsection{Data Collected by SK about Their Citizens in Order to Fight COVID-19}

Data are a key element to fight any pandemic, a lesson learned from different countries, including SK [6]. The variety and volume of data can assist in identifying hidden routes of transmission, people at a higher risk, and vulnerable links. To this end, we describe the variety and volume of data that SK used, compared to other countries, in Figure 2. As shown in Figure 2, SK used diverse types of data to handle this pandemic. In addition, the amount of data was also significantly higher, compared to all other countries across the globe. Furthermore, strict quarantine monitoring and the inflow of people's data were rigorously maintained and shared with the concerned authorities. Despite people's concerns, the SK government convinced citizens that the collected data will only be used for the intended purposes. Through collective efforts, a huge amount of data was collected that paved the way to curb the spread of COVID-19 effectively.

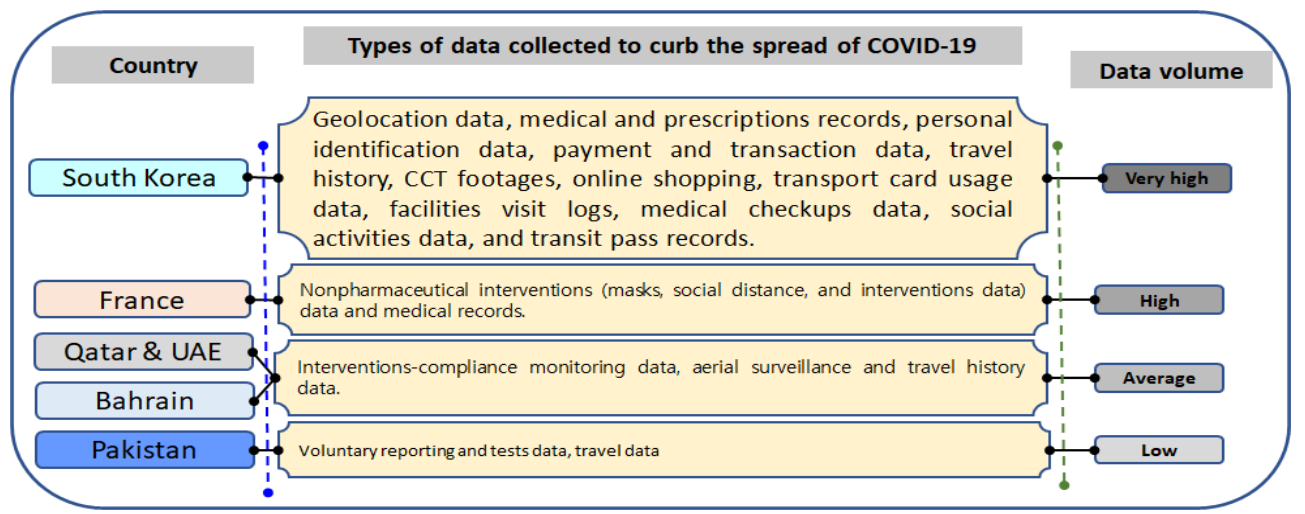

Figure 2. Overview and comparisons of data that SK used, compared to other countries.

At the beginning of the pandemic (e.g., January and February 2020), the SK government mainly collected data about people who had traveled/came from China (i.e., travel histories). Later, the government decided to use credit card and CCTV data in order to find potentially infected individuals. In the meantime, various apps for quarantine monitoring and movement tracking of travelers were also developed in March 2020. Upon the emergence of sporadic clusters at one church, the SK government started using multiple data (e.g., location data, purchased items, credit card use history, travel data, and CCTV footage) from April onward. Later in August 2020, another sporadic cluster emerged, and the SK government started using cellular network data in order to find exposed people. Currently, all forms of data listed in Figure 2 are being used to control the spread of this pandemic. Furthermore, sophisticated frameworks have also been developed to monitor the status of the pandemic and the vaccine roll out. In addition, more developments are expected in the near future, regarding COVID-19 control, mitigation, and economic recovery. 


\subsection{Development of an Integrated Epidemic Investigation Support System (EISS)}

Apart from variety of data collection, SK proposed and developed an integrated platform, named Epidemic Investigation Support System (EISS) after the 3rd month of the pandemic. EISS was developed through joint co-operation of many municipal governments. It was, indeed, a main step toward effectively curbing the spread of COVID-19. The architecture of the EISS, taken from study [5], is shown in Figure 3.

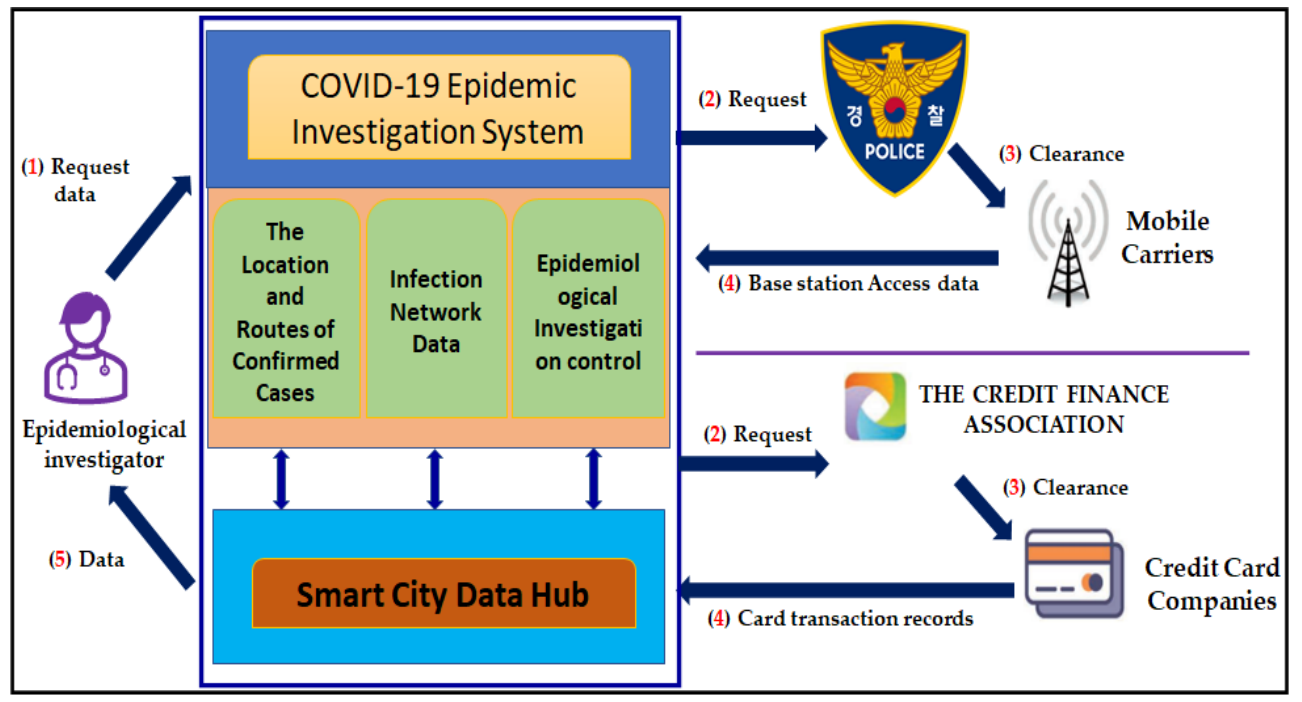

Figure 3. Overview of the EISS used by SK to fight the COVID-19 pandemic (Adopted from [5]).

The main uniqueness of the EISS is that the data collection and distributions with different authorities occurred in real time about the confirmed cases. Through EISS, not only was the spread restricted, but also the disease was contained across all regions of the country. In this system, some efforts were devoted to address the privacy issues. For example, a random ID was used rather than a precise cell number. By combining heterogeneous sources of data and the involvement of multiple authorities in the EISS, the pandemic was controlled in SK effectively. Due to its government's investments and higher role in the development of an EISS, its full-scale use was permissible despite privacy concerns. Additionally, people were informed as soon as there was a chance of infection. This multi-functional system played a vital role to address the COVID-19 implications effectively. In addition, this system was developed by keeping in mind the experiences of previous pandemics; that is why it has played a vital role in containing the ongoing pandemic.

\subsection{Innovative Mobile Applications}

Although many applications have been developed since the start of this pandemic, we describe three main applications that have revolutionized the epidemic handling in SK. We describe three main apps developed by the SK researchers and ministries.

\subsubsection{PreSPI}

Prevention System for Pandemic Disease Infection (PreSPI) is a unique application developed by the researchers of the Korea Advanced Institute of Science and Technology (KAIST) [7]. This app tracks the movement of COVID-19 patients, and alerts people to avoid taking similar routes taken by infected people. It provides a personalized score of the infection if someone has taken the same route. The concept of the app closely resembles the black-box of an airplane. This application was privacy preserved and an effective way to control the disease. The overview of the PreSPI is shown in Figure 4. The PreSPI has an ability to keep people away from infected places. In addition, this app is low cost, and can be downloaded from the app store. According to the developers of this app, SK's 
health authorities usually rely on credit card use records, public surveillance cameras, and other related data to track potentially infected individuals. This is time-consuming and has fueled privacy concerns. Meanwhile, this app addresses all these concerns, as this app was developed with privacy in mind.

\section{Overview of the PreSPI's Interfaces}

\section{1. 확진자 역학조사(웹)}

GPS 신호, 무선랜 신호, 기압계, 3 축 가속기, 자이로스코프와 같은 관성센서로부터 얻어지는 신호를 이용하여 이동 동선 기록

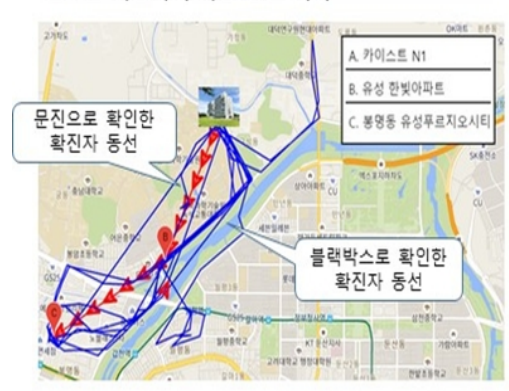

2. 바이러스 노출체크(앱)

확진자 동선과 개인 이동 동선의 중첩성을 확인하여 바이러스 노출 가능성 체크

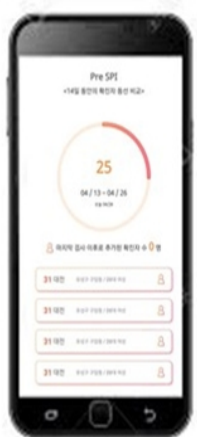

\section{3. 격리자 관리(앱)}

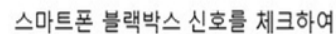
격리자의 격리 공간 이탈 여부 탐지

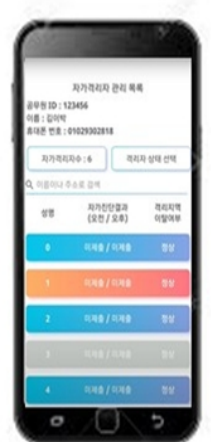

\footnotetext{
Major Services provided by the PreSPI

1. Epidemiological investigation of confirmed cases (web)

2. Virus exposure check (App)

3. Quarantine management (App)

Unique features of the PreSPI

$\rightarrow$ PreSPI uses the global positioning system, wireless local area network, Bluetooth, barometer and accelerometer built into most modern smartphones to follow the movement of individuals.

$\rightarrow$ The data collected from the "blackbox" of a phone will only be held in a so-called signal form, without any place names, with access being given to health authorities who need such information in their quarantine work to stem the spread of COVID-19.

$\rightarrow$ All information managed by PreSPI will be automatically erased TWO WEEKS after it is created.

$\rightarrow$ App will allow people to quickly and accurately determine if they have unknowingly come into close contact with infected persons.
}

Figure 4. Overview of the PreSPI app developed by the researcher of KAIST (find details at [7]).

2.3.2. Corona Self-Check Application Developed by the Ministry of Health and Welfare

The corona self-check application was a first step toward containment of this disease through technical means [8]. This app was developed by the Ministry of Health and Welfare (MoHW), South Korea. Through this app, self checking can be performed conveniently. The overview of the app is depicted in Figure 5.

The installation of this app was mandatory for all visitors, and it has played a vital role in constantly monitoring the health of visitors. Furthermore, it has proven effective to control the hidden transmission of COVID-19 and to save the residents of SK from contracting the disease. 

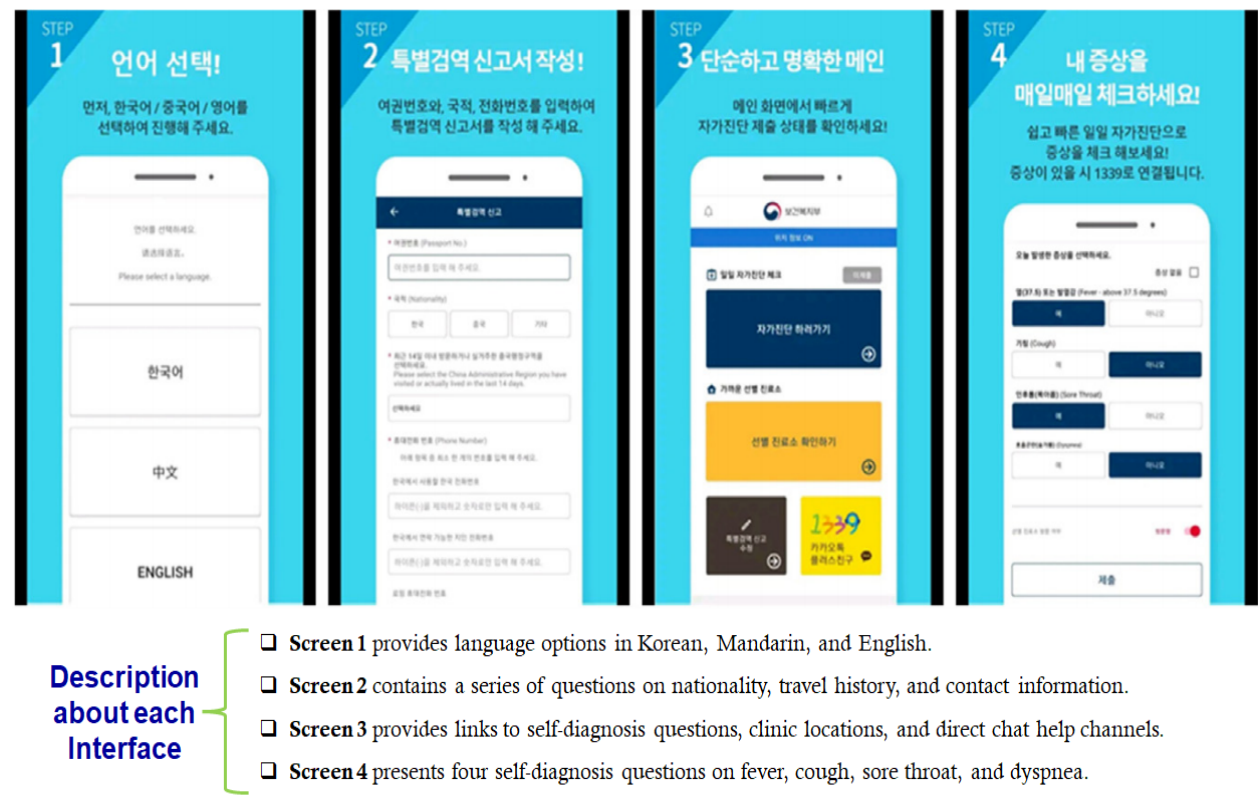

Figure 5. Overview of the self-check application developed by the MoHW.

2.3.3. Self-Quarantine Monitoring App Developed by the Ministry of Interior and Safety

The third app for self-quarantine monitoring was developed by the Ministry of Interior and Safety (MoIS) [8]. This app was designed to track people during quarantine and control quarantine breaches. The sole purpose to develop this app was to help local governments closely monitor a large group of potential patients with reduced labor and cost. The overview of the app is shown in Figure 6.

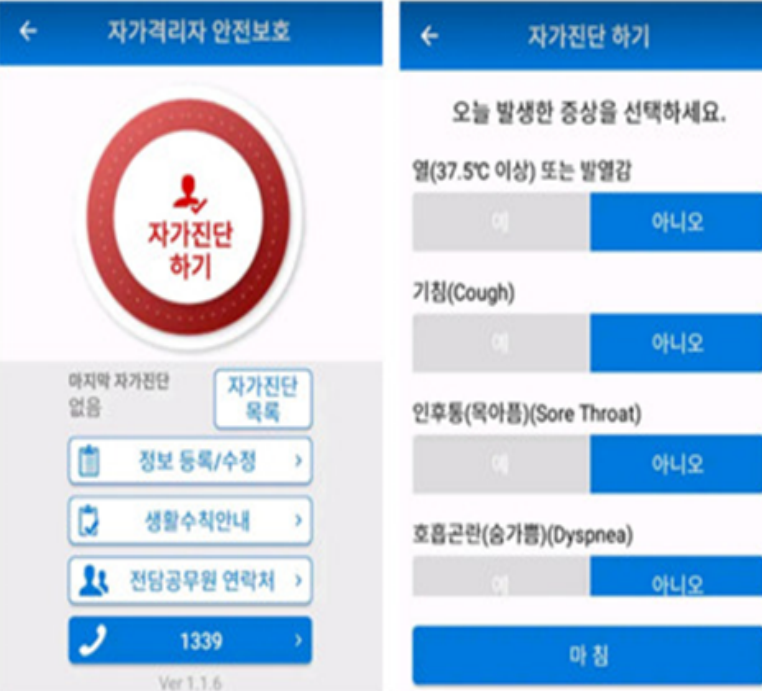

\section{Description of each interface}

Screen 1 provides links to self-diagnosis, health advice, and contact lines for health officials.

Screen 2 presents the same four selfdiagnosis questions as the MOHW app: fever, sore throat, cough, and dyspnea.

Figure 6. Overview of the self-quarantine monitoring app developed by MoIS. 
Apart from three recognized apps, the self-driving robot equipped with AI, developed by SK Telecom, was another major technical innovation to curb the spread of COVID-19 [9]. It has the ability to identify the violations of social distance measures, and it can alert people who are without masks. Furthermore, it can check the temperature of multiple people quickly. The joint efforts of the SK Telecom and Omron Electronics are one of the greatest examples of serving mankind during unprecedented times. The unique capabilities of the self-driving robot are described below.

- Temperature checking.

- Mask wearing.

- Disinfection building.

- Provision of hand sanitizers.

- $\quad$ Disinfect $30 \mathrm{~m}^{2}$ in $10 \mathrm{~min}$.

The overview and functioning of the self-driving robot equipped with AI and 5G technologies are given in Figure 7.

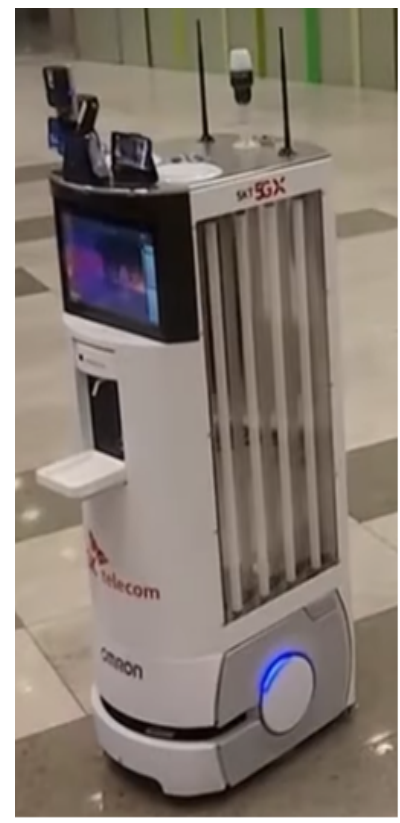

(a) Overview of robot

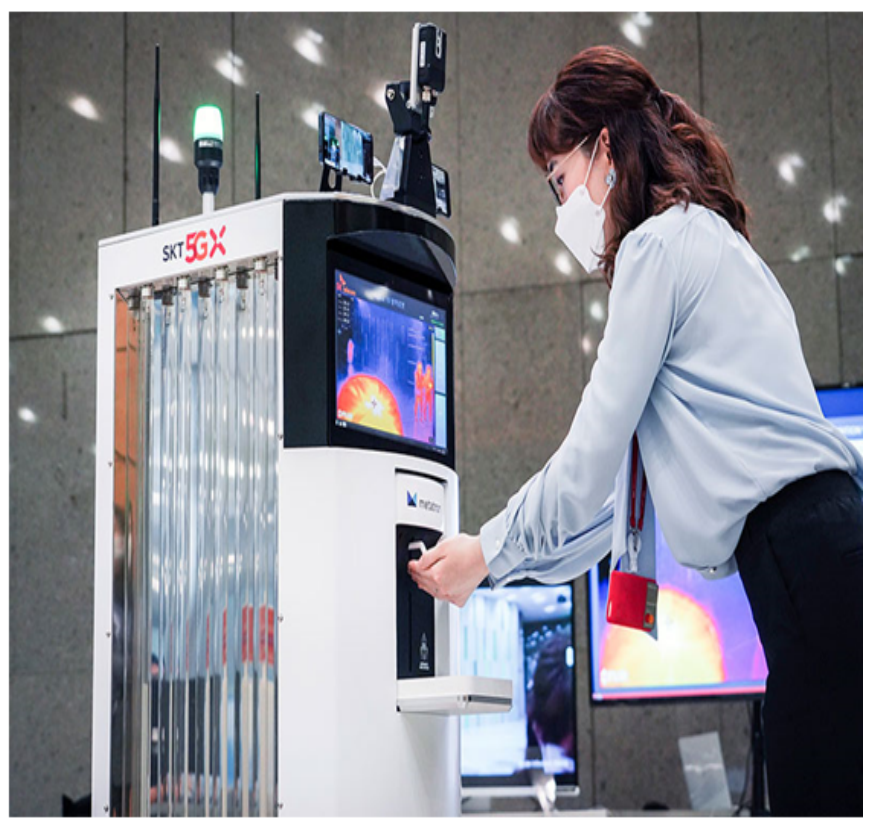

(b) Working of the Autonomous Robot

Figure 7. Self-driving robot equipped with latest technologies developed by SK Telecom.

Apart from these efficient apps and systems, a substantial number of digital solutions were developed across the SK. For example, the whole food supply chain was transformed from traditional to digital means. In addition, specific software were also developed to alert people to maintain distances in crowded spaces.

\section{Discussion and Lesson Learned}

In this section, we describe two sporadic clusters for which it was difficult to trace all people and how SK resolved those challenges. In addition, we discuss the major breakthrough that SK achieved in terms of people compliance, symptoms order, and other measures.

\subsection{Two Sporadic Clusters That Were Difficult to Trace and SK Role in Containing Spread}

The two most difficult sporadic clusters that emerged in the SK were the sporadic cluster at the Shincheonji church located in Daegu, SK, and the sporadic cluster at a gay club in the night life district of Seoul, SK [10]. Due to the nature of the participants, these two clusters put sufficient strain on the healthcare authorities. Thanks to the digital mechanism used by the SK, not only were all contacts identified, but also all members were 
tested in no time, containing the spread effectively. The overview of both clusters and the corresponding measures taken by the SK government are shown in Figure 8.

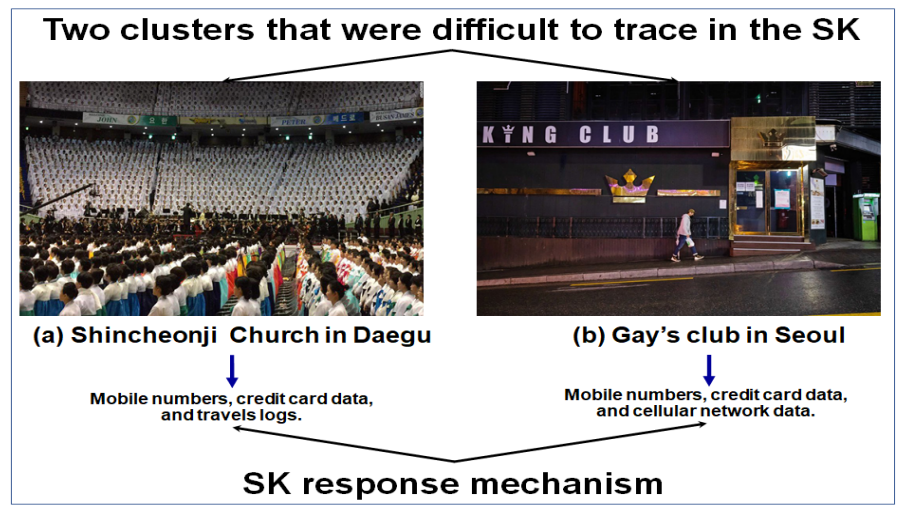

Figure 8. Overview of two sporadic clusters that were difficult to trace in the SK.

Although fine-grained access to the people's data (e.g., credit card, phone numbers, and pharmacy visits) in clusters was shunned by many participants, it was inevitable to control the disease spread. In the second cluster shown in Figure 8b, cellular network data played a vital role to trace all people who were present that night.

\subsection{People Compliance with the Government Measures}

In SK, the pandemic was controlled through socio-technical approaches. The people's compliance was a dominant factor to curb the spread of COVID-19 [11]. For example, the mask wearing rate was 100\%, and people avoided unnecessary travel. We present the findings of the Gallop Korea and Seoul National University Boramae medical center, gathered through surveying 2000 people, in Figure 9. From the analysis given in Figure 9, it can be concluded that the people's co-operation was a dominant factor in keeping the cases at a manageable level in SK.

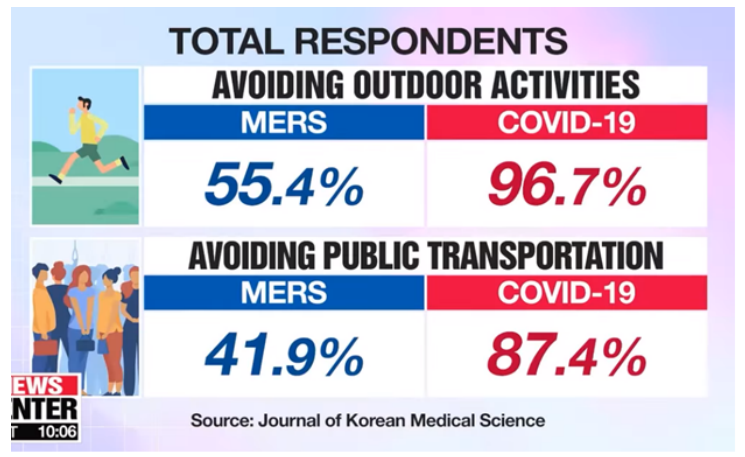

(a) Outdoor activities and travelling

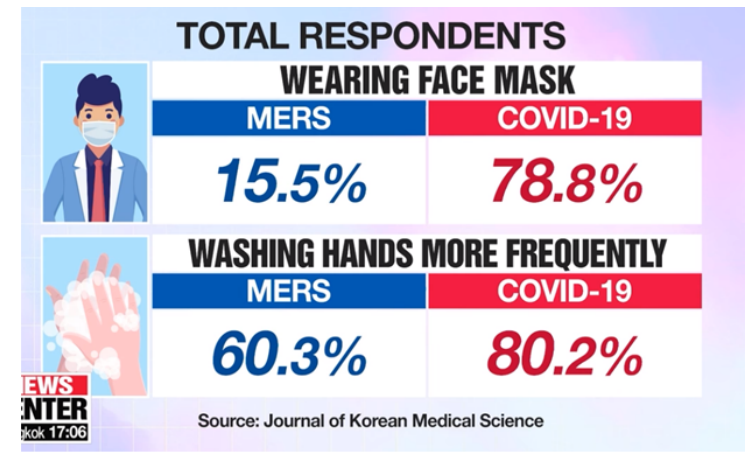

(b) Personal hygiene

Figure 9. Survey results: people's precautions in the ongoing pandemic and previous pandemic.

\subsection{SK Role in Identifying Distant Order of the Symptoms}

Apart from the digital innovation, SK was the first country who summarized and co-related the experiences of previous pandemics and that of COVID-19. To this end, a major contribution of the SK was the identification of the distant order of symptoms. The identification of the order of the symptoms can play a vital role in treating patients. SK researchers also identified that the order of symptoms varies in the COVID-19 context, which eventually makes it difficult to identify. We present the distant order of the symptoms identified by SK medics in Figure 10. With the help of these innovations, SK played a leading role in the fight against this pandemic. 


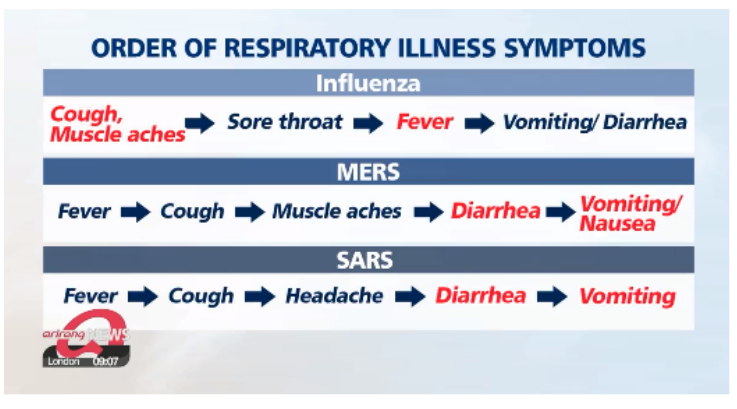

(a) Previous pandemics

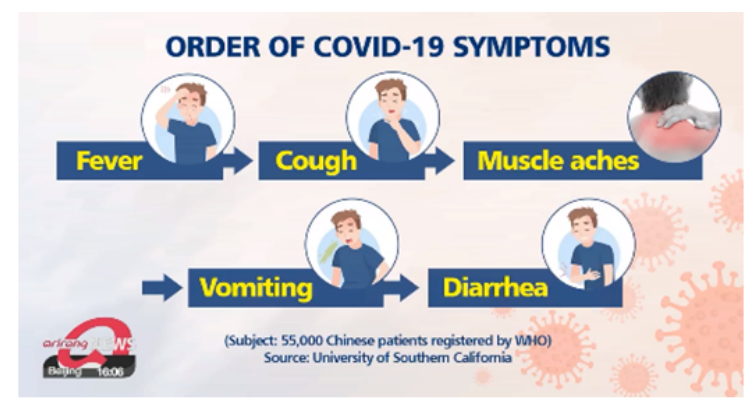

(b) ongoing pandemic (COVID-19)

Figure 10. Overview of distant order of the symptoms identified by SK medics.

\subsection{Why SK Remained in the Spotlight in Order to Contain This Deadly Disease}

The whole world suffered from this disease, yet SK managed to contain the spread effectively without significantly damaging its economy. We identified several reasons that made SK exemplary in its response to this pandemic. The main reasons are summarized as follows.

1. Enormous amount of data collection about people activities.

2. Robust and integrated platforms that can process heterogeneous sources data.

3. Transparent information sharing with relevant authorities.

4. Phase-specific applications development to control spread.

5. Extensive logging and monitoring of high risk facilities.

6. Closure of some facilities where social distance is difficult to maintain.

7. Providing monetary benefits to severely affected people.

8. Strong check and balance on the people coming from abroad.

9. Development of on-demand testing and treatment sites.

10. Rigorous and thorough care of elderly citizens.

11. Devising guidelines in close co-operation with the healthcare authorities.

12. Distributing and sharing disease dynamics with neighbor countries.

13. Restricting unnecessary transport during night time.

SK used all possible technical measures to fight this pandemic. However, privacy concerns were high for some measures, which need to be addressed in the near future [12]. For instance, in SK, when a person is infected with COVID-19, his/her personal information is shared to identify the exposed people. Although it is imperative to find potentially exposed people, on the other hand, it may violate the privacy of individuals. Hence, privacy-preserving mechanisms are needed to control these privacy violations. With the joint use of socio-technical approaches, SK is very close to winning the battle against this deadly pandemic. In addition, the vaccine inoculation is also increasing at a rapid speed, which is a vital sign for making SK pandemic-free in the near future. Furthermore, using digital means to mitigate and control other diseases also plays a vital role in this pandemic.

\section{Conclusions and Future Work}

In this brief article, we have summarized the experiences and lessons that can be drawn from the effective handling of the COVID-19 pandemic in SK. We have highlighted the main digital mechanisms adopted by SK in order to fight the COVID-19 pandemic, and their impact to keep daily cases at a manageable level. We have described the platforms, apps, and huge amount and variety of personal data that was used during this pandemic in the SK. Furthermore, we have described the two challenging clusters that emerged in SK, which were difficult to identity, but for which SK health authorities identified all participants/members effectively through digital means. We have described the role of SK in identifying the order of symptoms in COVID-19 patients and public actions. By following the SK model, future pandemics can be controlled effectively and without strict lock downs. In the future, we intend to explore the role of containment strategies and their 
adoption by the general public. Furthermore, analysis of digital solutions from privacy perspectives is another promising avenue for future research.

Funding: This research received no external funding.

Institutional Review Board Statement: Not applicable.

Informed Consent Statement: Not applicable.

Data Availability Statement: Not applicable.

Acknowledgments: The authors would like to thank the administration of the COVID journal for the kind consideration of this manuscript.

Conflicts of Interest: The authors declare no conflict of interest.

\section{References}

1. Skegg, D.; Gluckman, P.; Boulton, G.; Hackmann, H.; Karim, S.S.A.; Piot, P.; Woopen, C. Future scenarios for the COVID-19 pandemic. Lancet 2021, 397, 777-778. [CrossRef]

2. Burgos, R.M.; Badowski, M.E.; Drwiega, E.; Ghassemi, S.; Griffith, N.; Herald, F.; Johnson, M.; Smith, R.O.; Michienzi, S.M. The race to a COVID-19 vaccine: Opportunities and challenges in development and distribution. Drugs Context 2021, 10. [CrossRef] [PubMed]

3. Ahn, P.D.; Danture, W. Pushing the limits of accountability: Big data analytics containing and controlling COVID-19 in South Korea. Account. Audit. Account. J. 2021. [CrossRef]

4. Junghwan, K.; Kwan, M. An Examination of People's Privacy Concerns, Perceptions of Social Benefits, and Acceptance of COVID-19 Mitigation Measures That Harness Location Information: A Comparative Study of the US and South Korea. ISPRS Int. J. Geo-Inf. 2021, 10, 25.

5. Sangchul, P.; Choi, G.J.; Ko, H. Privacy in the Time of COVID-19: Divergent Paths for Contact Tracing and Route-Disclosure Mechanisms in South Korea. IEEE Secur. Priv. 2021, 19, 51-56.

6. Ahmad, N.; Chauhan, P. State of Data Privacy During COVID-19. Computer 2020, 53, 119-122. [CrossRef]

7. Contact Tracing System with Enhanced Privacy Protection Developed. Available online: https://en.yna.co.kr/view/AEN20200 610003400320 (accessed on 26 June 2021).

8. David, L.; Lee, J. Testing on the move: South Korea's rapid response to the COVID-19 pandemic. Transp. Res. Interdiscip. Perspect. 2020, 5, 100111.

9. SK Telecom Introduces 5G-Powered Autonomous Robot to Help Fight Against COVID-19. Available online: https://www. sktelecom.com/en/press/press-detail.do?idx=1461 (accessed on 20 June 2021).

10. Young, A.N.; Park, J.E.; Lee, D.H.; Hong, P.C. Balancing personal privacy and public safety during COVID-19: The case of South Korea. IEEE Access 2020, 8, 17132-171333.

11. Mo, J.W.; Jang, D.H.; Lee, J.Y. Social distancing and transmission-reducing practices during the 2019 coronavirus disease and 2015 Middle East respiratory syndrome coronavirus outbreaks in Korea. J. Korean Med. Sci. 2020, 35. [CrossRef]

12. Bing, L.; Zhu, H.; Xie, M. Quantifying Location Privacy Risks Under Heterogeneous Correlations. IEEE Access 2021, 9, 2387623893. 